University of Nebraska - Lincoln

DigitalCommons@University of Nebraska - Lincoln

Entomology Papers from Other Sources

Entomology Collections, Miscellaneous

1958

Tests With Poison Baits Against Cockroaches

C. S. Lofgren

USDA

G. S. Burden

USDA

Follow this and additional works at: https://digitalcommons.unl.edu/entomologyother

Part of the Entomology Commons

Lofgren, C. S. and Burden, G. S., "Tests With Poison Baits Against Cockroaches" (1958). Entomology Papers from Other Sources. 19.

https://digitalcommons.unl.edu/entomologyother/19

This Article is brought to you for free and open access by the Entomology Collections, Miscellaneous at DigitalCommons@University of Nebraska - Lincoln. It has been accepted for inclusion in Entomology Papers from Other Sources by an authorized administrator of DigitalCommons@University of Nebraska - Lincoln. 


\title{
TESTS WITH POISON BAITS AGAINST COCKROACHES
}

\author{
C. S. LOFGREN AND G. S. BURDEN \\ Entomology Research Division, Agr. Res. Serv., U. S. D. A.
}

Poison baits consisting of some food material with a toxicant such as phosphorus or boric acid have been used for many years for controlling the cockroaches (Mallis 1954, pp. 181-5). Recently Keller et al. (1956) reported that a bait consisting of cornmeal ( 73 percent), Coca-Cola sirup (25 percent), and Dipterex (2 percent) controlled Periplaneta spp. in homes for 30-60 days. This paper presents an evaluation of various poison-bait formulations against the American cockroach (Periplaneta americana [L.]) or mixed populations of this species with P. brunnea Burm. and the Australian cockroach ( $P$. australasiae $[F$.$] ) and against the German cock-$ roach (Blattella germanica [L.]).

\section{LABORATORY TESTS}

A large number of food materials were tested, separately and in combination, as 2-percent Dipterex poison baits. An acetone solution of insecticide was mixed with the food material. After the acetone evaporated, the bait was placed in small plastic vial lids. Small wads of cotton were soaked in the liquid baits to facilitate feeding by the cockroaches. The baits were exposed to the cockroaches in cylindrical screen cages or plastic refrigerator dishes. The cockroaches were also supplied with dog food and water. An excess of bait was used to permit ad libitum feeding. Two to six tests were run with each bait, with five American cockroach nymphs or five or ten German cockroach adults per test. Knockdown and mortality counts were taken after various periods of exposure. Results of tests with baits that killed at least 90 percent after 48 hours are recorded in Table 1.

Against American cockroaches, dextrin, cornstarch, and powdered sugar, alone or in combination with each other or different food materials, were the most effective dry baits, and Coca-Cola, root beer, and vanilla sirups were the most effective liquid baits. Powdered sugar was the most effective bait against German cockroaches. With this exception, German cockroaches accepted liquid baits more readily than dry baits whereas American cockroaches showed little preference.

\section{Tests in Rooms, Homes, and Dairy Barns}

A number of bait tests were run with selected food materials in rooms, homes, or dairy barns. The baits were prepared in the same manner as for the laboratory tests but not always with the same insecticide or concentration. Cornmeal was used in most formulations to add bulk, absorb moisture, and make the baits easier to apply.

Coca-Cola sirup and a mixture of cornmeal and powdered sugar containing 1 percent of Dipterex were tested against infestations of German cockroaches in rooms. The rooms were sealed so that no roaches could escape. Approximately 67 grams of bait was divided among three stations in each room. This was sufficient to provide ad libitum feeding. In another 
TABLE 1.-Attractiveness to Cockroaches of Various Food Materials in Baits Containing $2 \%$ of Dipterex. Laboratory Tests.

\begin{tabular}{cccccc}
\hline & \multicolumn{5}{c}{ Percent knockdown and kill after- } \\
\cline { 2 - 6 } Food Material & 1 & 2 & 4 & 24 & 48 \\
(figures indicate percent) & hour & hours & hours & hours & hours \\
\hline
\end{tabular}

American cockroaches

\begin{tabular}{|c|c|c|c|c|c|}
\hline Dextrin 50 , cornmeal $50 \ldots$ & 0 & 0 & 70 & 100 & 100 \\
\hline Dextrin 50 , cornstarch $50 \ldots \ldots$ & 0 & 0 & 60 & 100 & 100 \\
\hline Pepsi-Cola sirup & 0 & 0 & 40 & 100 & 100 \\
\hline Powdered sugar 25 , cornmeal 75 .. & 0 & 13 & 27 & 100 & 100 \\
\hline 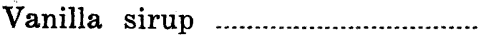 & 0 & 10 & 20 & 100 & 100 \\
\hline Root beer sirup & 0 & 0 & 10 & 100 & 100 \\
\hline Fructose water solution ...................... & 0 & 0 & 0 & 100 & 100 \\
\hline Coca-Cola sirup .................................... & 0 & 0 & 25 & 95 & 100 \\
\hline $\begin{array}{l}\text { Dextrin } 45, \text { dried ox blood } 10 \text {, } \\
\text { cornmeal } 45\end{array}$ & 0 & 0 & 15 & 85 & 100 \\
\hline 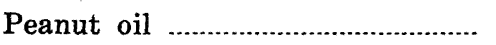 & 0 & 0 & 0 & 95 & 95 \\
\hline Cornstarch & 0 & 0 & 15 & 90 & 95 \\
\hline Dextrin & 0 & 0 & 27 & 93 & 93 \\
\hline Dextrin 50 , peanut oil 50 & 0 & 0 & 30 & 90 & 90 \\
\hline Brewers' yeast (dried) .......................... & 0 & 0 & 10 & 90 & 90 \\
\hline Dried ox blood ..................................... & 0 & 0 & 0 & 90 & 90 \\
\hline Dextrin $331 / 3$, dried brewers' & & & & & \\
\hline yeast $331 / 3$, cornstarch $331 / 3 .$. & 0 & 0 & 0 & 90 & 90 \\
\hline Maltose water solution ..................... & 0 & 0 & 0 & 90 & 90 \\
\hline 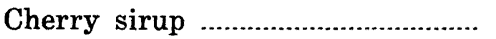 & 0 & 0 & 10 & 80 & 90 \\
\hline $\begin{array}{l}\text { Cornmeal } 331 / 3 \text {, dextrin } 331 / 3, \\
\text { dried brewers' yeast } 331 / 3 \ldots . . .\end{array}$ & 0 & 0 & 10 & 80 & 90 \\
\hline
\end{tabular}

German cockroaches

\begin{tabular}{|c|c|c|c|c|c|}
\hline Powdered sugar ……………….............. & 0 & 5 & 80 & 100 & 100 \\
\hline Cornmeal 75 , powdered sugar 25 . & 0 & 23 & 56 & 100 & 100 \\
\hline Root beer sirup ...................................... & 0 & 0 & 60 & 100 & 100 \\
\hline 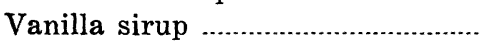 & 0 & 0 & 20 & 100 & 100 \\
\hline Orlando fly food* & 0 & 5 & 15 & 100 & 100 \\
\hline Strawberry sirup & 0 & 0 & 10 & 100 & 100 \\
\hline Sucrose water solution & 0 & 10 & 10 & 90 & 100 \\
\hline Maltose water solution & 0 & 0 & 0 & 80 & 100 \\
\hline Coca-Cola sirup ……………....... & 0 & 0 & 10 & 90 & 95 \\
\hline Cherry sirup ………………… & 20 & 20 & 40 & 80 & 90 \\
\hline $\begin{array}{l}\text { Dextrin } 25, \text { dried ox blood } 10, \\
\quad \text { cornmeal } 25, \text { Coca-Cola } \\
\quad \text { sirup } 40\end{array}$ & 0 & 0 & 20 & 80 & 90 \\
\hline
\end{tabular}

* $25 \%$ raw egg, $6 \%$ powdered milk, $34.5 \%$ honey, and $34.5 \%$ malt extract. 
Lofgren and Burden: Tests With Poison Baits

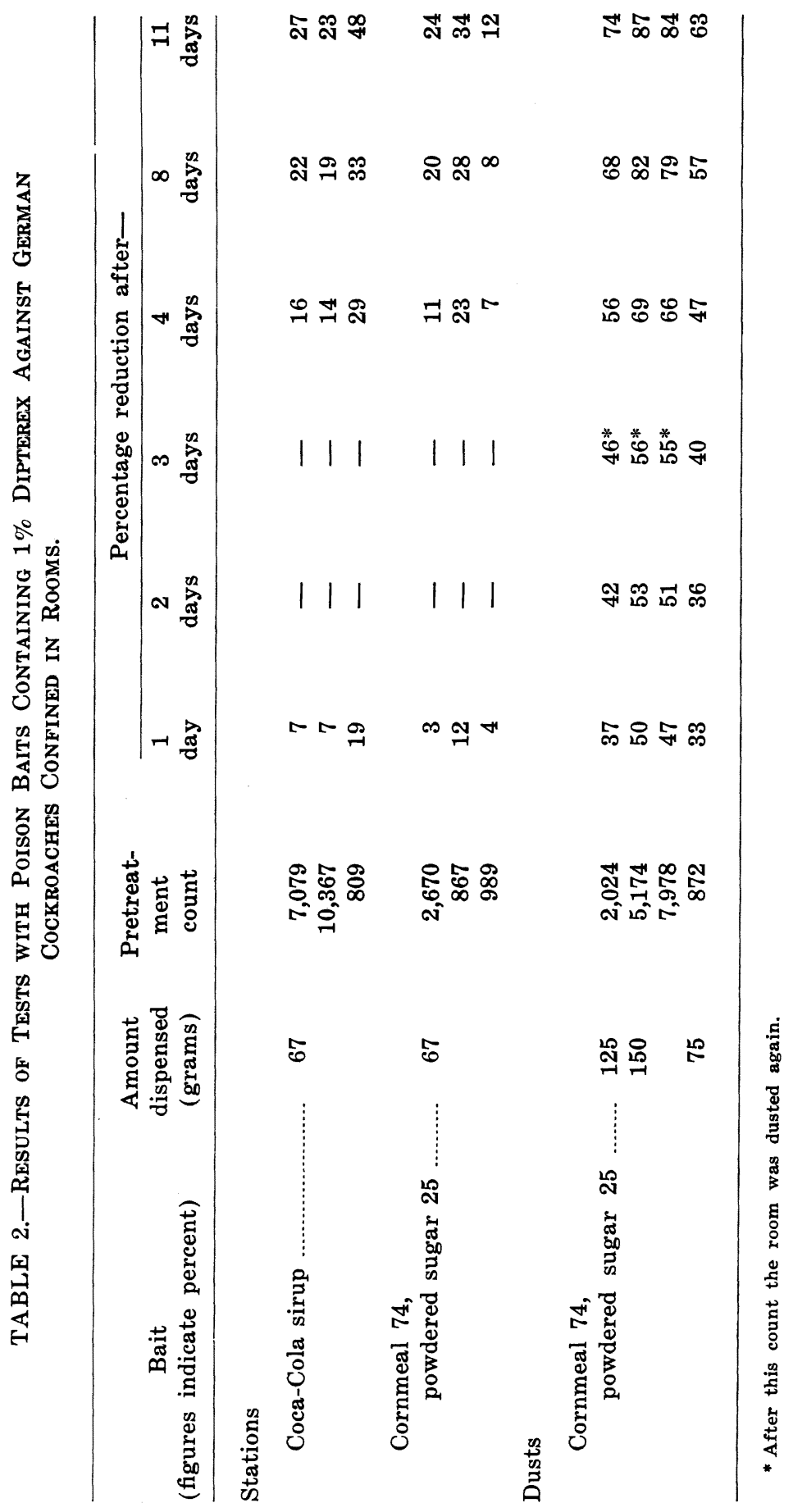




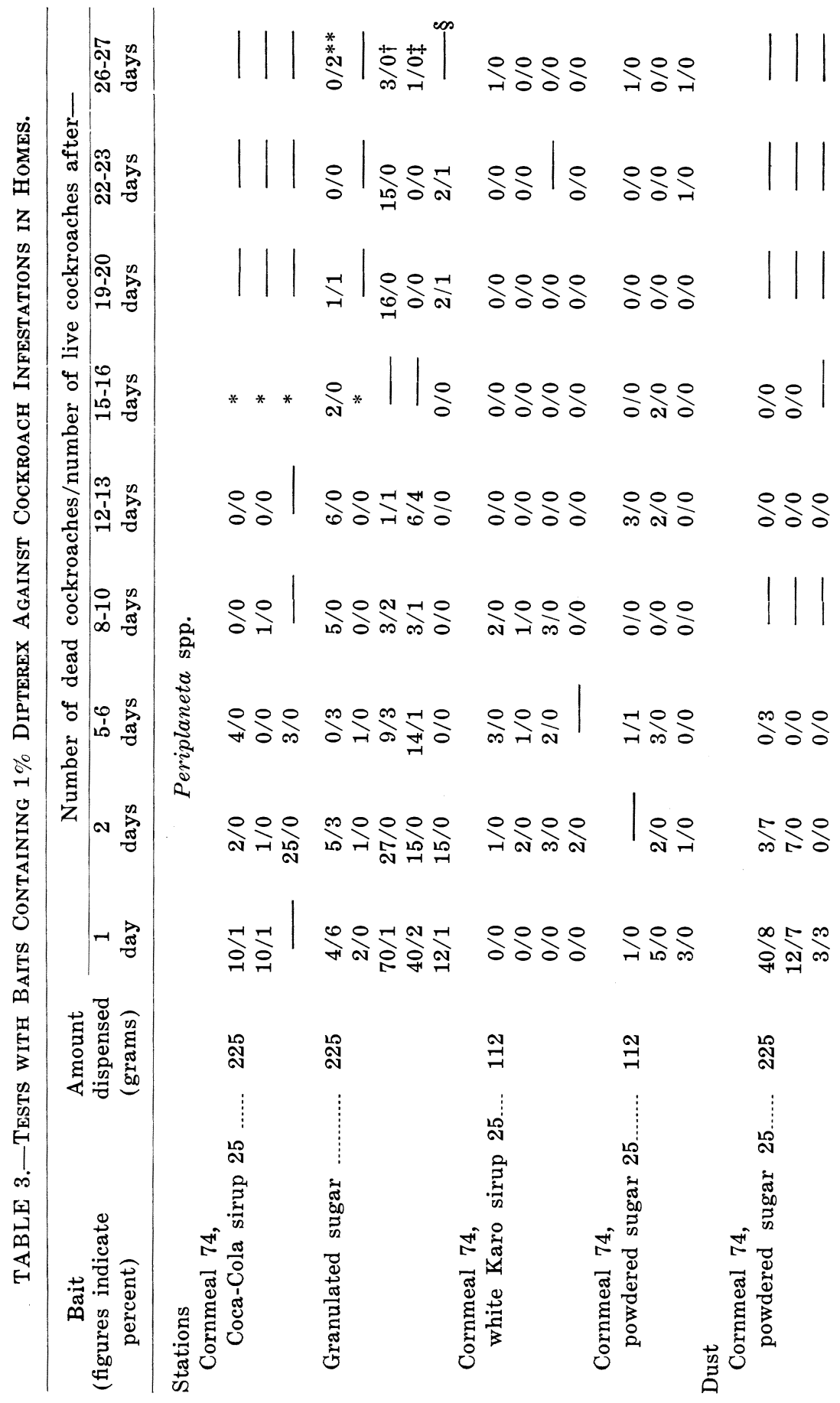


Lofgren and Burden: Tests With Poison Baits

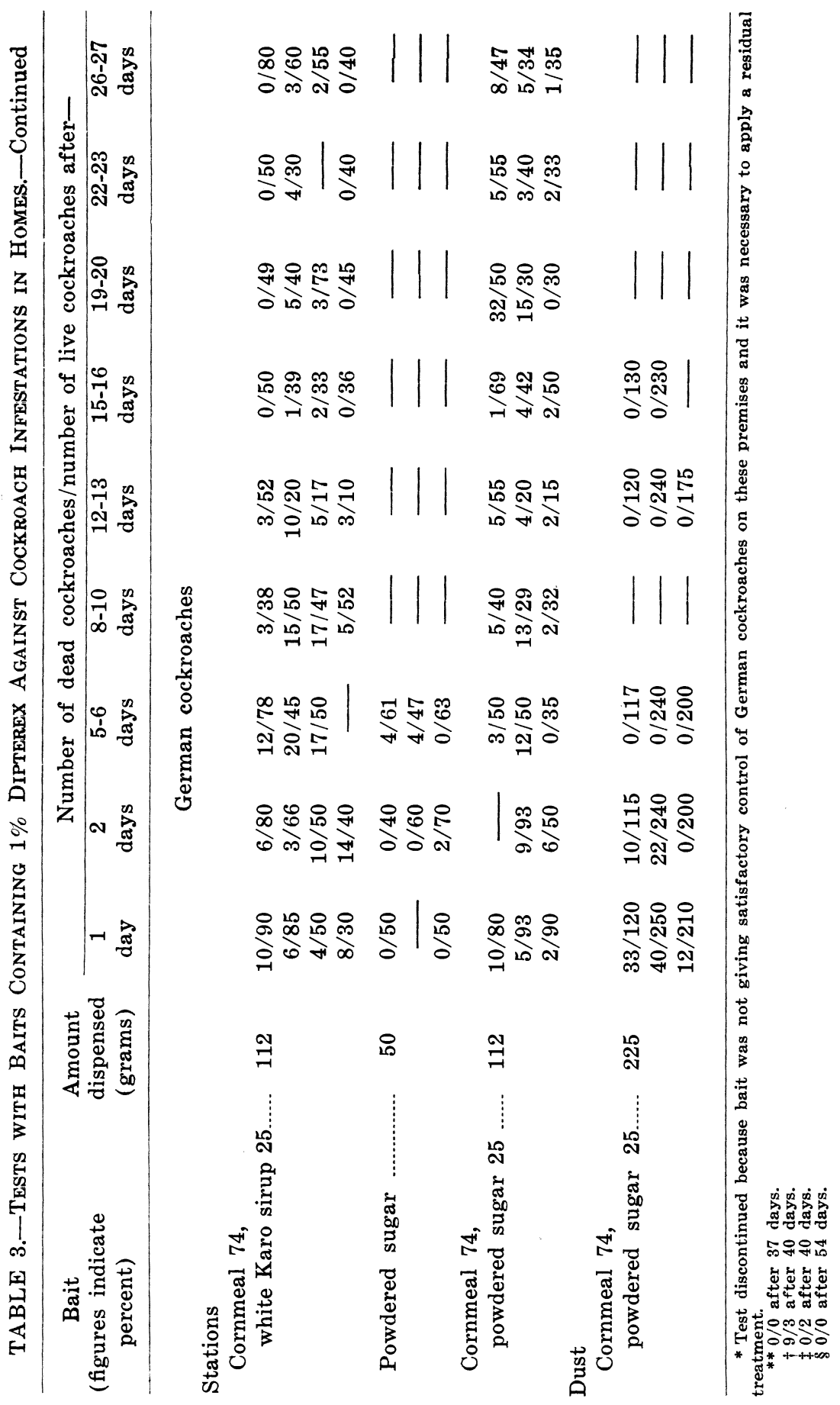


The Florida Entomologist $\quad$ Vol. 41, No. 3

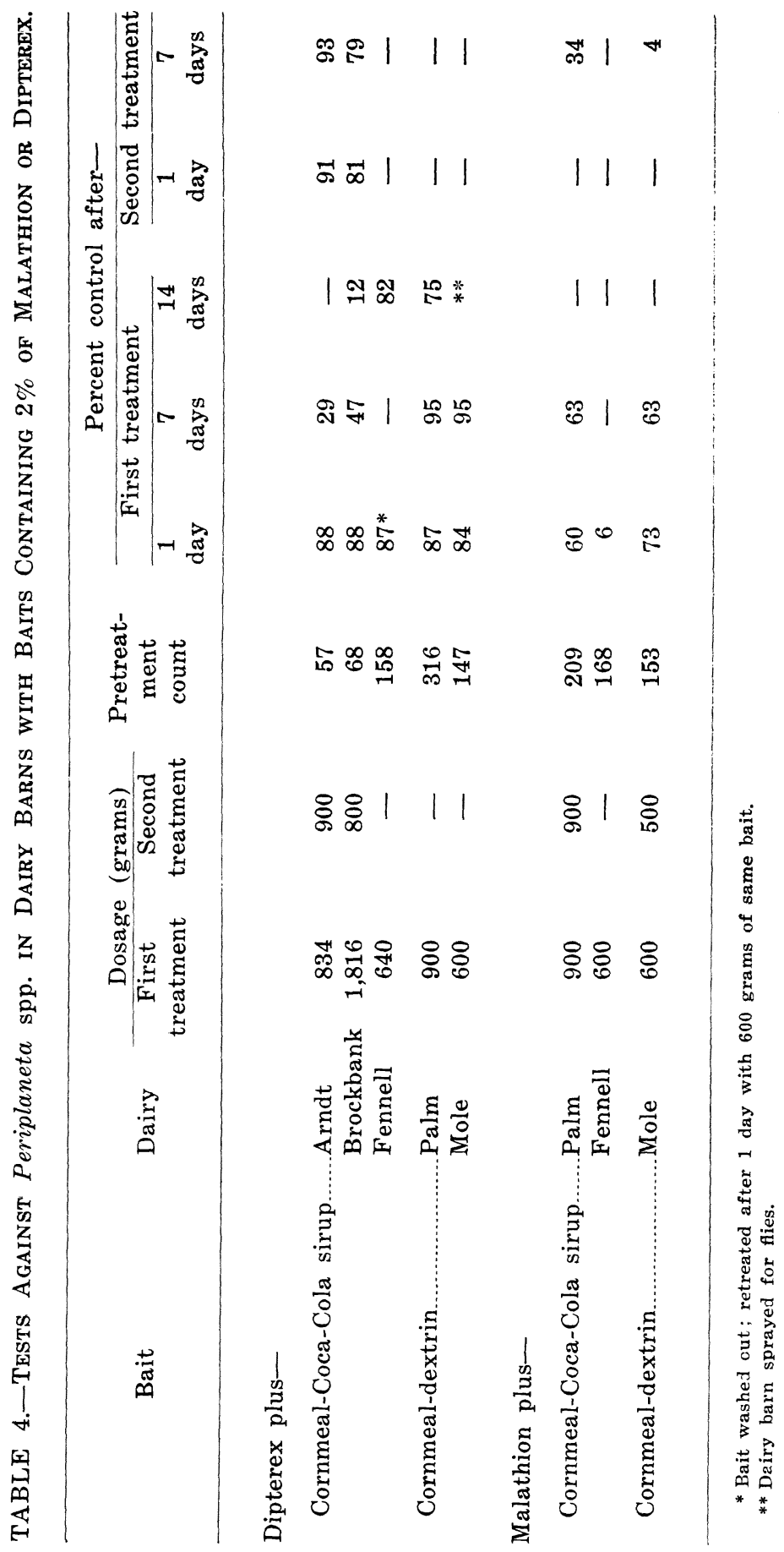


test the cornmeal-powdered-sugar bait was applied as a dust from a small plastic catsup dispenser. In three of the rooms in this test it was necessary to replace bait that was eaten or became scattered and was swept out when mortality counts were taken.

Table 2 shows the cornmeal-sugar bait applied as a dust to be the most effective, but that at the stations the Coca-Cola bait was better.

Tests in homes were made with baits containing 1 percent of Dipterex in the following food materials: granulated sugar, powdered sugar, and mixtures of cornmeal plus white Karo sirup, powdered sugar, or Coca-Cola sirup. In one series the baits were put in small piles in out-of-the-way areas or exposed in nut cups or envelopes. The cups were set on flat surfaces and the envelopes stapled to vertical surfaces in or behind cupboards, behind sinks, refrigerators, and stoves and in other places where they would not be washed or swept away and were not readily accessible to children. In a second series of tests a mixture of finely ground cornmeal and powdered sugar plus the toxicant was applied as a dust with small plastic catsup dispensers. The treatments were evaluated by making regular inspections of the premises for dead and live roaches. The results given in Table 3 show that all the baits reduced the populations of Periplaneta but none were appreciably effective against the German cockroaches.

In 1955 and 1956 tests were run against large mixed populations of Periplaneta in several dairy barns. The baits contained 2 percent of Dipterex or malathion, 73 percent of cornmeal, and 25 percent of Coca-Cola sirup or dextrin. Small piles of the bait were placed in corners, cracks, and in other places where it would not be washed or swept away. When less than 75 percent control was obtained after one week, a second application was made.

In most of the dairies roach control was determined by taking flash pictures at night. After the barns were vacated in the evening, the cockroaches crawled from their hiding places looking for food, and a large proportion of them were located near or in the feed troughs and in the feed rooms. Control was based on the reduction in the number of cockroaches in three or four pictures before and after treatment. When low populations were present, it was possible to make an accurate visual count with the aid of a dim light. Percent control in the Fennell dairy was based on such visual counts. After two weeks most of the bait had been destroyed, and counts were discontinued. The results are presented in Table 4.

Both baits gave good control when Dipterex was used as the toxicant ( 75 to 95 percent after one or two treatments, based on the original pretreatment count). When malathion was used, control ranged from 4 to 34 percent.

\section{SUMMARY}

Laboratory and field tests with various poison bait formulations against cockroaches are presented. In laboratory tests with 2-percent Dipterex baits, powdered sugar showed the greatest attractiveness to German cockroaches (Blattella germanica [L.]), and dextrin and cornstarch alone or in combinations were the most attractive to nymphs of American cockroaches (Periplaneta americana [L.]).

In rooms and homes none of the baits tested against German cockroaches gave satisfactory control. Baits consisting of 1 percent of Dipterex in gran- 
ulated sugar or mixtures of cornmeal plus Coca-Cola sirup, powdered sugar, or white Karo sirup were effective in reducing infestations of Periplaneta spp. in homes. Seventy-five to 95 percent control of Periplaneta spp. in dairy barns was obtained with baits containing 2 percent of Dipterex in cornmeal plus dextrin or Coca-Cola sirup. When malathion was used as the toxicant, control ranged from 4 to 34 percent.

\section{Literature Cited}

Keller, J. C., P. H. Clark, C. S. Lofgren, and H. G. Wilson. 1956. Cockroach control. Pest Control $24(9): 12,14,17,19-20$.

Mallis, Arnold. 1954. Handbook of pest control. McNair-Dorland Co., New York. $1068 \mathrm{pp}$.

From August 17 to August 25, 1960, there will take place in Vienna the ELEVENTH INTERNATIONAL CONGRESS OF ENTOMOLOGY. Interested persons, not yet having received a circular letter, are asked to contact the secretary's office of the Congress, Vienna I., Burgring 7, by postcard as soon as possible. Further information will be sent to them immediately. 